\title{
Autumn Quarterly Meeting, 1993
}

The Autumn Quarterly Meeting was held at Kensington Town Hall, London on 27 October 1993.

\section{Business meeting}

The business meeting was attended by 44 Members of the College.

\section{Minutes}

The minutes of the Spring Quarterly Meeting held at University College of Swansea, Wales on 15 and 16 April 1993 were approved and signed.

\section{Registrar's report}

Since the summer meeting, the College has been actively making progress on a number of major items of work.

\section{Among those nearing completion}

The response to the Ashworth Hospital Inquiry is currently being finalised, for review at the next meeting of the Council. A consensus statement on the use of high dose antipsychotic prescribing has been approved as a Council Report. This important statement has been awaited as the first clear guidance on the use and safety of high dose prescribing. In addition to its issue as a Council Report, the bulk of the guidelines have been adopted by the British National Formulary in its forthcoming edition. A press statement will take place today, and a research project into the epidemiology of apparently drug-related sudden death is to be undertaken by the Psychopharmacology Group. The guidelines will also be turned into audit standards by the College Audit and Information Technology Office (CAITO). The inaugural meeting of the Sub-Committee of CAITO has now taken place and plans for a regular series of audit standards are well advanced. These standards will be for the use of the membership, informing local medical audit activities. An explanatory article will shortly be appearing in the Psychiatric Bulletin.

A Continuing Medical Education Department has now been established in the College, incorporating some of the work of the Programmes and Meetings Committee and linking with a new CME journal to be edited by the immediate past-President. A considerable sum is being sought from external funds to further expand this essential activity.
The College had presented written evidence to the House of Commons Select Committee on Health's inquiry into mental health services. This response, which runs to over 40 pages plus references and background material, has been a major undertaking and the Officers are grateful to those Members and Fellows who contributed to it. It is not yet certain if or when the committee will accept oral evidence. The College has also presented evidence to the Department of Health's internal review on the legal powers for the care of mentally ill people in the community. This $\mathrm{DoH}$ review was partly a response to the College's own report on community supervision orders which. although not adopted, was accepted as an important contribution to the review. It remains to be seen whether the increased powers will be passed into law by parliament and whether they will be effectively implemented. We have, of course, in our evidence emphasised the need for community resources to complement the increased powers of key workers.

The College has recently begun a number of major new initiatives in the public affairs and educational arena. The President has established a working party to delineate the role and responsibilities of the consultant psychiatrist in the multidisciplinary team. This exercise has not been carried out since the Presidency of Professor Kenneth Rawnsley and has been made necessary by the many rapid changes in the health and mental health services. The officers of specialist sections have been asked to take part and a report is anticipated early in 1994. Any members with views on the matter may write directly to the President. This report will set College policy for our relationships with other professional groups for the next decade.

The Council Report of 1990 on Psychiatric Practice and Training in British Multiethnic Society is seen as an important statement of College policy. In view of the continuing concern both within and outside the College on various aspects of ethnicity, a small group has been formed under the chairmanship of the Dean to take forward and implement policy decisions.

The Chief Medical Officer's report on specialist training is awaited in its final form. In anticipation of its contents, Dr Mike Harris, Sub-Dean. is chairing a working group on the educational strategy of the College and will report in due course on the most appropriate strategy for the career structure proposed by Calman. A diploma in psychiatry has been proposed and work will go forward to explore its feasibility.

Another major piece of work to be tackled shortly is a new policy statement on community 
care, the old Public Education document being very out of date. This will involve all specialist sections and will lead to new policy and new public education documentation. The discovery that some of our policy statements are out of date has led to a proposal that all new statements should have a lifespan determined by Council when accepted as Council reports. All old policy statements are being reviewed and each will be dropped as irrelevant, modified to bring them up to date or rewritten until no College policy statement is available without an identified currency.

The College has also been requested to take part in an important element of the work of the
London Implementation Group, which has set up a mental health reference group to guide it when modifying the acute health sector of London's 16 health authorities and 33 boroughs. The Registrar is a member of this group and is seeking, with other members of the group, to ensure that the work is of an appropriate duration and has sufficient legitimacy to have a genuine impact in supporting and developing the mental health services of London including primary, secondary and tertiary services.

Professor CHRIS THOMPSON, Registrar, Royal College of Psychiatrists

\section{NHS Management Executive guidance for staff on relations with the public and the media}

Concern has been expressed within the College in respect of paragraph 27 of the above NHS Management Executive guidance, which could be interpreted as meaning that staff who chose to consult their Members of Parliament might face disciplinary action.

The College has therefore sought clarification from the Department of Health, and the following written assurance has been received from the NHS Management Executive.
"Staff are completely free to consult their MP any time on any issue, and by doing so, they would not be liable for any disciplinary action. This is their constitutional right and the guidance does not aim to compromise this position."

VANessa CAmeron, Secretary, Royal College of Psychiatrists

\section{Business Meeting}

There will be a Business Meeting of the College, to be held in the Council Room at the Royal College of Psychiatrists at $4.30 \mathrm{pm}$ on Wednesday 23 March 1994. All Members of the College are welcome to attend this meeting.

\section{Agenda}

1. Confirmation of the minutes of the previous meeting on 2 February 1993. These minutes will be tabled at the meeting and thereafter published in the Psychiatric Bulletin in April. 2. Obituary.

3. Report of the Registrar.

4. Resolutions (if any). 